
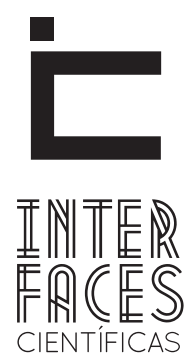

DIREITO

\title{
DA NECESSIDADE DE RELEITURA DO PRINCÍPIO DA ANTERIORIDADE ELEITORAL
} OF THE NEED OF REREADING FOR THE PRINCIPLE OF ELECTORAL PRIOR LA NECESIDAD RELEITURA DEL PRINCIPIO DE LA ANTERIORIDAD ELECTORAL

Diogo Basilio Vailatti ${ }^{1}$

\section{RESUMO}

0 presente estudo traz elementos para interpretar e reanalisar o princípio constitucional cravado no artigo 16 da Constituição da República Federativa do Brasil, conhecido por princípio da anterioridade eleitoral. Trazem-se análises acerca do Supremo Tribunal Federal, dos efeitos das decisões proferidas em controle concentrado e difuso, da função dos princípios, bem como da necessidade de harmonizar os preceitos da anterioridade eleitoral e da moralidade administrativa, de forma que se consolidem as ideias democráticas e republicanas no sistema jurídico brasileiro.
Guilherme Piccinin de Oliveira²

\section{PALAVRAS-CHAVE}

Princípio da Anterioridade Eleitoral. Moralidade Administrativa. Processo Eleitoral. Valores Constitucionais. Supremo Tribunal Federal. 


\section{ABSTRACT}

This study provides elements for interpret and review the constitutional principle spiked in article 16 of the Constitution of the Federative Republic of Brazil, known as the principle of electoral prior. Bring up analyzes of the Supreme Court, the function of the principles, the effect of the decision in the constitutionality actions, as well as the need to harmonize the ideas of the electoral precedence and the administrative morality, in order to consolidate the democratic and republican ideas in the Brazilian legal system.

\section{RESUMEN}

Este estudio aporta elementos para interpretar y revisar el principio constitucional pinchos en el artículo 16 de la Constitución de la República Federativa de Brasil, conocido como el principio de la elección anterior. Abra análisis de la Corte Suprema, los efectos de las decisiones en el control concentrado y difuso, el papel de los principios y la necesidad de armonizar las reglas de la elección y la moral administrativa previa con el fin de consolidar las ideas democráticas y republicano en el ordenamiento jurídico brasileño.

\section{KEYWORDS}

Principle of Electoral Prior - Public Morality - Electoral process - Constitutional values - The Supreme Court.

\section{PALABRAS CLAVE}

Principio de la elección previa; Moralidad Administrativa; Proceso electoral; valores constitucionales; el Tribunal Supremo. 


\section{INTRODUÇ̃̃̃o}

A evolução legislativa em matéria eleitoral é cada vez mais presente, mormente pelo clamor popular pela obrigatoriedade do bom gasto das receitas públicas, e objetiva evitar que novos casos de corrupção ocorram na esfera pública.

No sistema eleitoral brasileiro, no qual eleições ocorrem de dois em dois anos, analisar o princípio da anterioridade eleitoral deixa de ser mera liberalidade, mas sim uma necessidade para que exista a consolidação do princípio republicano e das garantias e direitos fundamentais.

Tal análise, porém, navega por mares tormentosos, uma vez que a interpretação literal do artigo 16 da Constituição Federal, o qual preceitua o princípio da anterioridade eleitoral, pode afastar que se apliquem imediatamente normas eleitorais benéficas ao sistema jurídico, caso estas sejam publicadas a menos de um ano das eleições, e o Direito, enquanto fato social, não pode se distanciar dos valores e dos anseios sociais.

Desta forma, o presente estudo visa debater a compatibilidade de harmonização entre o indigitado princípio, a moralidade pública e a transparência política almejada por todos.

\section{MÉTODO}

O presente estudo utilizou-se do método indutivo para chegar ao seu objetivo final. Para tanto, partiu-se das funções do Supremo Tribunal Federal e da análise dos princípios para verificar se o atual posicionamento da Suprema Corte relativo ao tema em apreço, é condizente com a carga valorativa expressa no princípio da anterioridade. Ademais, a pesquisa teve caráter eminentemente documental e bibliográfico.

\section{RESULTADOS}

0 resultado aqui alcançado confunde-se com a conclusão. Ao longo do estudo, percebeu-se que o aspecto valorativo existente dentro do princípio da anterioridade eleitoral permite sua utilização ou não conforme o caráter benéfico, para a coletividade, da alteração da legislação eleitoral.

\section{DA FUNÇÃO DO SUPREMO TRIBUNAL FEDERAL NASACÕESDIRETASDEINCONSTITUCIONALIDADE [ADI/ADIN] E NAS DE CONTROLE DIFUSO}

Conquanto o tema em apreço seja diretamente afeto ao Direito Eleitoral, fazendo parte deste, é indissociável a ideia do referido ramo jurídico com o Supremo Tribunal Federal e os efeitos de suas decisões.

O Supremo Tribunal Federal é o órgão jurisdicional máximo da nação, tendo, como precípua função, a guarda e proteção das normas, garantias e princípios constitucionais federais.

Cumpre destacar que a Constituição da República de 1988 dividiu as competências explícitas do Supremo Tribunal Federal em: “a) originária (art. 102, I, “a” a “r”), b) recursais ordinária (art. 102, II), e c) recursal extraordinária (art.102,III)" (LENZA, 2012, p. 727)

Para melhor entender o tema em análise, será necessário perceber os efeitos das decisões proferidas pelo Supremo Tribunal Federal no controle concentrado e no difuso de constitucionalidade.

O controle concentrado de constitucionalidade é exercido pelo Supremo Tribunal Federal, no qual possui a Ação Direta de Inconstitucionalidade (ADI ou ADIn) como uma de suas principais ferramentas. Conforme pontua Pedro Lenza (2012, p. 337) “o que se busca com a ADI genérica é o controle de constitucio- 
nalidade de ato normativo em tese, abstrato, marcado pela generalidade, impessoalidade e abstração".

Desta forma, é necessário que a leitura da lei (sentido latu) impugnada em sede de Ação Direta de Inconstitucionalidade seja feita sob a luz da Lei Fundamental, em detalhada averiguação, para evitar a vigência de institutos que contenham mandamentos antagônicos ao sistema constitucional pátrio.

Em não sendo detectada inconstitucionalidade do texto apreciado, a lei mantém os efeitos produzidos anteriormente. Entretanto, ao ser declarada inconstitucional, padecerá, no todo ou em parte, de total nulidade, com retroação dos efeitos por ela causados (ex tunc), como se nunca tivesse existido. Pode, ainda, caso exista excepcional interesse público ou por razões de segurança jurídica, a Suprema Corte fixar momento diverso para que a decisão produza efeitos, conforme artigo 27 da Lei 9.868 de 1999.

Por outro lado, o controle difuso (ou de exceção) é aquele que pode ser realizado por todo e qualquer órgão jurisdicional, sendo tal controle o mais acessível ao cidadão - uma vez que o julgamento da inconstitucionalidade do ato ou norma pretendida aplica-se diretamente ao litígio do qual é parte - não havendo legitimados constitucionais específicos para sua propositura, diferentemente daqueles explicitados em rol taxativo contido no artigo 103 da Lei Maior.

Tal controle, entretanto, dá-se de forma incidental, de modo que mesmo não sendo parte do pedido a declaração de inconstitucionalidade da lei, a análise da questão constitucional arguida é imprescindível para o correto deslinde da contenda.

Ao revés do controle concentrado (ou direto, ou ainda, via de ação), os efeitos dos julgamentos realizados por via do controle difuso não se estendem para toda a sociedade, ou seja, deixam de ter efeitos erga omnes, oponíveis em face de qualquer pessoa, e passam a ter efeitos inter partes, vinculando apenas as partes litigantes no exato processo do qual foi verificada a necessidade do controle de exceção, impossibilitando, desta forma, que a decisão seja transferida para casos semelhantes.

De outra forma, o controle de exceção também se diferencia essencialmente da via de ação em relação a seus efeitos: enquanto desta, via de regra, emanam efeitos ex tunc, retroagindo-se à data da validade da lei ou ato normativo, aquela possui efeitos ex nunc, garantindo efeitos não-retroativos, não alcançando, portanto, fatos passados. Neste sentido, conclui-se que a lei, em sede de controle difuso, continua em plena vigência, não incidindo, pontualmente, no caso em que fora julgada inconstitucional.

Apesar da maior intimidade de tal controle para com o cidadão, Manoel Gonçalves Ferreira Filho (2012, p. 58) destaca que um grande inconveniente de tal controle é "a possibilidade de juízes apreciarem diferentemente a validade de uma lei, com a consequência de ser aplicada a uns e não a outros; a incerteza quanto ao direito até a decisão final do Tribunal mais alto, ou especializado", sendo forçosa a conclusão de que, por tais razões, a insegurança jurídica torna-se parte integrante do controle difuso de constitucionalidade, ainda que de acesso mais amplo.

Com base nas linhas até aqui traçadas, debruçar-nos-emos, a seguir, sobre o conceito de princípio, e enfim às discussões sobre o Recurso Extraordinário que fixou entendimento sobre o princípio da anterioridade eleitoral, bem como uma avaliação rigorosa entre o embate do supracitado princípio frente ao princípio da moralidade, indispensável a qualquer disposição que reja os processos e normas eleitorais.

\section{CONCEITO DE PRINCÍPIO}

O vocábulo princípio traz em seu bojo diversas conotações, sendo certo que sua análise é imprescindível para o deslinde do tema em exposição. 
O professor Allaôr Caffé Alves (2011, p. 150) tece a seguinte definição:

Princípio, no sentido ontológico, é aquilo pelo que a coisa existe, e, no sentido lógico, é aquilo que nos dá a conhecer os conceitos, as proposições e as inferências de modo coerente, numa articulação ideal correta ou válida. Os princípios, lógicos, portanto, bem refletidos, a par de sua natureza estruturadora do pensamento formal, são dirigentes do conhecimento. (Grifos no original).

Em análise analógica de tal pensar, temos que os princípios, no ramo jurídico, são os carros-chefes, os pontos a serem alcançados por todo o ordenamento jurídico. Devem ser vistos como o eixo-motriz que impulsiona o processo legislativo e, via reflexa, enquadram-se e tornam-se os anseios, objetivos e perspectivas da sociedade.

Por outro lado, Robert Alexy (1994, p. 14) explica sobre as funções dos princípios:

[...] os princípios são normas jurídicas que ordenam que se realize algo na maior medida possível, em relação com as possibilidades jurídicas e fáticas. Os princípios são, por conseguinte, mandados de otimização que se caracterizam porque podem ser cumpridos em diversos graus e porque a medida ordenada de seu cumprimento não depende só de possibilidades fáticas, mas também das possibilidades jurídicas. 0 campo das possibilidades jurídicas está determinado por meio de princípios e regras que jogam em sentido contrário.

Desta forma, uma vez que também está previsto dentro do ordenamento jurídico, tem-se que princípio é uma norma, igualmente às regras, porém com aplicações diversas.

Diferenciando regras e princípios, explicita o ministro do Supremo Tribunal Federal, Gilmar Mendes (2014, p. 85):

Os princípios seriam aquelas normas com teor mais aberto do que as regras. Próximo a esse critério, por vezes se fala também que a distinção se assentaria no grau de determinabilidade dos casos de aplicação da norma. Os princípios corresponderiam às normas que carecem de mediações concretizadoras por parte do legislador, do juiz ou da Administração. Já as regras seriam as normas suscetíveis de aplicação imediata.
Podemos concluir, assim, que enquanto as regras têm efeito imediato, certo e sabido frente à determinada situação, o princípio tem valor ponderativo sobre a questão, podendo ser a ele dado valor imensurável ou ínfimo, ainda que em conflito com outros princípios, diante do caso concreto.

A liberalidade do uso e apuração do valor do princípio é infinitamente maior do que o da regra, a qual por si só é fechada, restando-lhe a hermenêutica para seu melhor entendimento e aplicação.

Neste sentido, os princípios são os guias dos institutos jurídicos, devendo servir de parâmetro para a edição, interpretação e aplicação doutras normas jurídicas.

No entender de José Cretella Júnior (1997, p. 7), “princípios de uma ciência são as proposições básicas, fundamentais, típicas que condicionam todas as estruturações subsequentes. Princípios, neste sentido, são os alicerces da ciência”.

Nota-se que a atuação do princípio é de ser o objetivo valorável maior em um sistema jurídico, perfazendo meta sistêmica seu conjunto, em consequente inviabilidade das regras que contrariem seus preceitos.

Tal entendimento, enquanto extraído da via puramente teórica, por conseguinte, dá azo a maiores e melhores estruturações normativas e disciplinares do ordenamento jurídico, refletindo diretamente nas necessidades da sociedade como um todo.

\section{PRINCÍPIO DA ANTERIORIDADE ELEITORAL E A ALTERAÇÃO DE PARADIGMA COM A EMENDA CONSTITUCIONAL}

O processo de criação das previsões legais engloba três momentos diversos: elaboração, promulgação e publicação. A norma é válida perante o ordenamento após ser elaborada e promulgada. Todavia, para 
produzir efeitos, ainda precisa ser publicada no Diário Oficial (órgão que exterioriza os atos administrativos praticados) e ultrapassar o período de vacância da norma (GONÇALVES, 2009, p. 38-39).

A redação em vigor do artigo 16 da Carta Maior é fruto da quarta emenda constitucional que modificou o texto produzido pelo poder constituinte originário. Tal como a previsão atual, a redação original da Carta Política instituía o princípio da anterioridade na esfera eleitoral, porém, com alcance diverso, uma vez que o marco para contagem do prazo anual partia da promulgação, e não da publicação da norma, como ocorre no presente momento.

Com a modificação em análise, a Carta Magna revestiu o princípio da anterioridade eleitoral de caráter ainda mais democrático. Se o objetivo do princípio em análise é o de evitar que existam alterações na legislação que possam impossibilitar o debate político e a alternância do poder, nada mais justo que a publicação, momento no qual existe a divulgação da lei elaborada para a sociedade, seja o marco da contagem do prazo anual.

Além disto, no novo cenário, o prazo de vacância já está expresso pela Carta Magna, qual seja: um ano. Percebe-se que o ditame constitucional amplia a regra geral de quarenta e cinco dias previsto no artigo $1^{\circ}$ da Lei de Introdução ao Direito Brasileiro justamente para aumentar o espaço temporal de discussão entre toda a sociedade.

Destarte, percebe-se que a alteração promovida pelo poder reformador, muito embora em uma primeira leitura possa não parecer tão significativa, reforçou o objetivo de proteção ao processo eleitoral democrático. Todavia, ao aplicar o princípio em análise, o Supremo Tribunal Federal percebeu que nem todas as alterações eleitorais são danosas, mesmo próximas ao pleito, motivo pelo qual passou a fixar requisitos para a aplicação da anterioridade, os quais veremos com maior detença no item sete do vertente estudo.

\section{REQUISITOS DO STF PARA AVERIGUAR O PRIN- CÍPIO DA ANTERIORIDADE ELEITORAL E O JULGA- MENTO DO RE 633.703}

Muito em função dos períodos ditatoriais e das perseguições partidárias ocorridas no Brasil, falar-se em alteração da legislação eleitoral, próxima ao pleito, é assunto delicado que necessita de uma devida construção teórica para que se maximize o sistema democrático e republicano.

Deve-se notar que nem toda a modificação das regras do jogo é maléfica, motivo pelo qual não faria sentido criar um método estanque que impossibilite o aperfeiçoamento do sistema político de forma imediata.

Na ação direta de inconstitucionalidade 3.741, o ministro Ricardo Lewandowski, baseado em julgamento relatado pelo ministro Celso de Mello, notou que o Supremo Tribunal Federal definiu que o princípio da anterioridade eleitoral só é desrespeitado, mesmo que exista alteração na legislação eleitoral em prazo inferior a um ano, quando ocorrer: 1) rompimento da igualdade de participação dos partidos políticos e dos respectivos candidatos no processo eleitoral; 2) a criação de deformação que afete a normalidade das eleições; 3) a introdução de fator de perturbação do pleito; ou 4) a promoção de alteração motivada por propósito casuístico.

Com a fixação de tais requisitos, a questão parecia pacificada. Contudo, posteriormente, fruto de uma intensa pressão popular, em 7 de junho de 2010, poucos meses antes da eleição de 3 de outubro de 2010, um nova alteração na legislação eleitoral, por meio da Lei Complementar 135/2010, popularmente conhecida como "Lei da Ficha Limpa", colocou em choque novamente tais pressupostos. Seria ou não aplicável à nova legislação na eleição que se aproximava? Ao analisar tal possibilidade, a Suprema Corte assim manifestou-se: 
LC 135/2010, denominada Lei da Ficha Limpa. Inaplicabilidade às eleições gerais de 2010. [...] O pleno exercício de direitos políticos por seus titulares (eleitores, candidatos e partidos) é assegurado pela Constituição por meio de um sistema de normas que conformam o que se poderia denominar de devido processo legal eleitoral. [...] Toda limitação legal ao direito de sufrágio passivo, isto é, qualquer restrição legal à elegibilidade do cidadão constitui uma limitação da igualdade de oportunidades na competição eleitoral. Não há como conceber causa de inelegibilidade que não restrinja a liberdade de acesso aos cargos públicos, por parte dos candidatos, assim como a liberdade para escolher e apresentar candidaturas por parte dos partidos políticos. E um dos fundamentos teleológicos do art. 16 da Constituição é impedir alterações no sistema eleitoral que venham a atingir a igualdade de participação no prélio eleitoral. [...] 0 princípio da anterioridade eleitoral constitui uma garantia fundamental também destinada a assegurar o próprio exercício do direito de minoria parlamentar em situações nas quais, por razões de conveniência da maioria, o Poder Legislativo pretenda modificar, a qualquer tempo, as regras e critérios que regerão o processo eleitoral. $A$ aplicação do princípio da anterioridade não depende de considerações sobre a moralidade da legislação. 0 art. 16 é uma barreira objetiva contra abusos e desvios da maioria, e dessa forma deve ser aplicado por esta Corte. A proteção das minorias parlamentares exige reflexão acerca do papel da Jurisdição Constitucional nessa tarefa. A jurisdição constitucional cumpre a sua função quando aplica rigorosamente, sem subterfúgios calcados em considerações subjetivas de moralidade, o princípio da anterioridade eleitoral previsto no art. 16 da Constituição, pois essa norma constitui uma garantia da minoria, portanto, uma barreira contra a atuação sempre ameaçadora da maioria. (BRASIL, 2011, n.p.). Grifo nosso).

Percebe-se que o Supremo Tribunal Federal, em que pese o caráter moralizador da Lei Complementar $135 / 2010$, a qual objetivava ampliar o rol de ilegibilidades, declarou sua inaplicabilidade para as eleições de 2010, uma vez que existiria suposta restrição ao exercício da capacidade eleitoral passiva de todo e qualquer cidadão, o que iria contra os preceitos anteriormente já fixados.

Partindo-se do posicionamento adotado pela Corte Maior, surge uma premente necessidade de refle- xão sobre o princípio da anterioridade eleitoral e dos seus requisitos. Qual é o alcance da norma prevista no artigo 16 da Carta Maior? Para alcançar tal resposta é necessário compreender a função dos direitos fundamentais na sociedade moderna.

Após a Segunda Guerra Mundial e a tragédia que devastou a Europa, os textos constitucionais são guiados pelo horizonte valorativo da sociedade. Para evitar que o Direito seja banhado pelo pensamento imoral, os princípios otimizam a aplicação do ordenamento, de forma que a ordem constitucional viva verdadeiro processo de moralização da ciência jurídica. Marcelo Schenk Duque (2014, p. 139) pontua sobre os valores e os princípios:

\begin{abstract}
[...] valores e princípios, conquanto apresentem uma relação de similitude, diferenciam-se em um ponto essencial. Aquilo que no modelo dos valores é prima facie o melhor, é no modelo dos princípios prima facie devido. [...] não há nenhuma dificuldade em se transpor da constatação de que determinada solução é a melhor (relacionada a valor) do ponto de vista constitucional, para a constatação de que ela é constitucionalmente devida (relacionada ao princípio).
\end{abstract}

Em uma perspectiva neoconstitucional, o princípio da anterioridade eleitoral deve ser visto com base nos valores sociais nele representados. A Constituição Federal de 1988, além de implantar um sistema democrático e republicano, objetiva que a moralidade alcance a esfera pública, tanto assim o é que a positivou como princípio constitucional em seu artigo $5^{\circ}$, caput. Desta forma, em que pese o posicionamento do Supremo Tribunal Federal, a Lei Complementar 135/2010 deveria ter sido aplicada de imediato nas eleições de 2010, uma vez que não existiria uma alteração persecutória no sistema eleitoral, mas sim a concretização de um preceito constitucional até então já existente. Aliás, não se vislumbra qualquer incompatibilidade entre os preceitos anteriormente citados e a aplicação imediata da "Lei Ficha Limpa".

A discussão acima tratada, muito embora possa parecer datada, não o é. Em um sistema político como 
o brasileiro, no qual eleições ocorrem a cada dois anos, é necessário delinear o alcance do princípio da anterioridade eleitoral. Muito mais do que simplesmente afastar alterações positivas ao sistema jurídico brasileiro, o princípio pretende proteger o regime democrático, de forma que, atualmente, ao aplicá-lo, os questionamentos devem ser centrados na ideia de moralização e avanços da legislação eleitoral.

A interpretação adotada pelo Supremo Tribunal Federal, em sede de Recurso Extraordinário, possui efeitos inter partes, contudo, servirá de precedente para o julgamento de todas as demais ações relativas ao processo eleitoral, conforme requisitos já explanados anteriormente. Desta forma, como a Corte Maior pode futuramente rever seu posicionamento, já nas próximas eleições, necessário faz-se uma releitura do princípio destacado no artigo 16 da Lei Maior, inserindo-se, por sua vez, o princípio da moralidade administrativa como arrimo do princípio da anterioridade eleitoral, a fim de alcançar a mais ampla transparência acerca do processo democrático pátrio.

\section{DA RELEITURA DO PRINCÍPIO DA ANTERIORIDA- DE ELEITORAL À LUZ DO PRINCÍPIO DA MORALI- DADE ADMINISTRATIVA}

Com a análise da Lei complementar 135/10, decidiu-se pela constitucionalidade de sua previsão. Contudo, no que tange à sua aplicação para as eleições de 2010, como sua alteração deu-se a poucos meses da mesma, ficou definido que a restrição das candidaturas por crimes praticados pelos parlamentares ou por rejeição de contas com irregularidades insanáveis de improbidade administrativa iria à contramão da proteção às minorias.

Ocorre que, por mais que o princípio supracitado vise proteger as minorias, há de se reconhecer que o espírito do artigo 16 da Lei Fundamental pauta-se em não permitir que haja golpe político que exclua candi- datos ou partidos, como por diversas vezes já ocorreu na história do Brasil, o que é completamente diverso de afastar-se do processo eleitoral candidatos que não seguem os ditames constitucionais da moralidade administrativa.

Desta forma, tem-se que em uma balança dos valores constitucionais, o princípio da anterioridade eleitoral deve ser interpretado em consonância com o princípio da moralidade administrativa, traduzindo-se, assim, em nova e verdadeira forma de defesa a todo o eleitorado, fortalecendo sobremaneira a transparência da administração pública, o princípio republicano e o Estado Democrático de Direito.

Portanto, partindo-se da devida adequação entre ambos os princípios constitucionais, tem-se que alterações benéficas ao processo eleitoral não devem ser afastadas pelo princípio da anterioridade eleitoral, insculpido no artigo 16 da Carta Magna, uma vez que seu objetivo é exatamente aperfeiçoá-lo, não devendo haver óbices para o aperfeiçoamento do sistema eleitoral.

\section{CONCLUSÃO}

Em um país que vivencia seus primeiros passos democráticos, verificar os limites e possibilidades de alteração na seara eleitoral torna-se essencial.

As necessidades da sociedade brasileira frente aos disparates políticos que se perpetuam não podem ficar sem escuta. Limitar a interpretação do artigo 16 à sua literalidade é ignorar o objetivo sistêmico de coadunar e sopesar todos os princípios constitucionais em face de um fato determinado.

Neste sentido, tratando-se de princípio, o qual, conforme visto, tem maior carga valorativa que uma regra, é necessário ampliar sua abrangência, sabedores que qualquer regra jurídica benéfica implantada no ordenamento jurídico não tem o condão de macu- 
lar o sistema eleitoral, ao contrário, serve de aperfeiçoamento aos ditames democráticos.

Desta forma, notou-se que a releitura do princípio da anterioridade eleitoral, em consonância com o princípio da moralidade administrativa, é medida imprescindível para a consolidação da transparência política e eleitoral, bem como para o fortalecimento dos princípios basilares do Estado Democrático de Direito.

\section{REFERÊNCIAS}

ALEXY, Robert. Derecho y razon practica. México:

Distribuciones Fontamara, 1993.

ALMEIDA, Roberto Moreira de. Curso de direito eleitoral. 6.ed. São Paulo: Juspodivm, 2012.

ALVES, Allaor Caffé. Lógica - pensamento formal e argumentação. 5.ed. São Paulo: Quartier Latin, 2011.

CRETELLA JÚNIOR, José. Os cânones do direito administrativo. Brasília: Revista de Informação Legislativa, 1997.
DUQUE, Marcelo Schenk. Curso de direitos

fundamentais: teoria e prática. São Paulo: Revista dos Tribunais, 2014.

DWORKIN, Ronald. Taking rights seriously.

Cambridge: Mas Harvard University Press, 1978.

FERREIRA FILHO, Manoel Gonçalves. Curso de

direito constitucional. 38.ed. rev. e atual. São Paulo: Saraiva, 2012.

GONÇALVES, Carlos Roberto. Direito civil brasileiro. 7.ed. São Paulo: Saraiva, 2009.

LENZA, Pedro. Curso de direito constitucional. 16.ed. São Paulo: Saraiva, 2012.

MENDES, Gilmar Ferreira; BRANCO, Paulo Gustavo Gonet. Curso de direito constitucional. 9.ed. São Paulo: Saraiva, 2014. 
Data da submissão: 29 de abril de 2016

Avaliado em: 9 de maio de 2016 (Avaliador A) Avaliado em: 15 de maio de 2016 (Avaliador B) Aceito em: 17 de maio de 2016
1. Bacharel em Direito pela Faculdade de Direito de São Bernardo do Campo. Especializando em Direito Tributário no Instituto Brasileiro de Estudos Tributários (IBET). Mestrando em Direito pela Universidade Nove de Julho (UNINOVE). Pesquisador Capes/Prosup) Advogado. Palestrante e conferencista. E-mail: diogo_bv23@hotmail.com

2. Bacharel em Direito pela Faculdade de Direito de São Bernardo do Campo. Advogado. E-mail: guilherme.piccinin@gmail.com 